\title{
Heritability and genetic correlations between weight gains in Murrah, Mediterranean, and Jaffarabadi buffaloes raised in Brazil, employing Bayesian inference
}

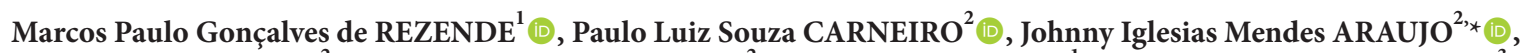 \\ André Campêlo ARAUJO ${ }^{2}$ (D), Barbara Machado CAMPOS $^{2}$ (D), Riccardo MORETTI ${ }^{1}$ (D), Leonardo Gomes SITORSKI ${ }^{3}$ (D), \\ Wéverton José Lima FONSECA ${ }^{2}$ (D), Riccardo BOZZI ${ }^{4}$ (D), Carlos Henrique Mendes MALHADO ${ }^{2}$ (D) \\ ${ }^{1}$ National Association of Cattle Breeders of Piedmontese Breed, Carrù, Italy \\ ${ }^{2}$ Southwestern State University of Bahia, Campus of Jequié, Bahia, Brazil \\ ${ }^{3}$ Department of Animal Sciences, North Dakota State University, Fargo, North Dakota, USA \\ ${ }^{4}$ DADRI - Animal Science Section, University of Firenze, Firenze, Italy
}

Received: 22.05 .2019

- $\quad$ Accepted/Published Online: 28.01 .2020

Final Version: 00.00 .2020

\begin{abstract}
The request for products of buffalo origin (beef and milk) has been growing throughout the years, and to meet this demand it is necessary to obtain animals with high levels of performance guaranteed through generations. Thus, it is of paramount importance to know the heritability of the desired traits in order to genetically improve the populations. The objective was to estimate the genetic parameters for weight gain from birth to weaning (BWGW) and from weaning to 12 months of age (WGW12) of Murrah (4675), Mediterranean (405), and Jaffarabadi (766) buffaloes raised in Brazil. Bayesian inference with the bi-trait model was used. The direct heritability in the Mediterranean and the Jaffarabadi breeds presented low to moderate estimates whereas the Murrah breed was medium for the two traits considered. Heritability estimates for maternal effect were low for BWGW and decreased with advancing age but remained present until 12 months of age. The genetic correlations found between all traits indicate that selection for increased weight gain at younger ages leads to increased weight gain at 12 months and it is thus possible to select at this age since the weight gains are highly correlated in all breeds.
\end{abstract}

Key words: Genetic correlation, growth, heritability, performance

\section{Introduction}

Buffaloes were firstly reported in Asia and Africa, and then they became widespread in the rest of the world [1] as work animals, as well as for beef and milk production [2], because they possess a remarkable rusticity and resistance to endo- and ectoparasites, and to several infectious diseases [3]. However, this species presented reduced productive performances compared to other livestock species due to the lack of genetic improvement programs.

Currently, with the high demand for buffalo products, it would be important to reduce the unproductive period of the animals, to allow them to compete with other species like cattle, poultry, and pigs that are rather precocious. Periodical control of the animal's weight gain is a simple technique of measurement, which can be used as a phenotype for genetic improvement programs to produce precocious animals [4]. Research focused on the productive and reproductive characteristics of buffaloes $[5,6]$ has been carried out in Brazil, but it would

\footnotetext{
*Correspondence: johnny-iglesias@hotmail.com
}

be necessary to improve the knowledge about genetic evaluation of weight gain in buffaloes.

Genetic parameter estimation allows forecasting a selection response [7], which is very important for the implementation and the efficiency of the genetic improvement program. Genetic correlations among parameters are useful in selection schemes in order to maximize the selection response and eventually to increase the economic return [8]. Correlated responses could be used to produce an animal with a functional biotype in a shorter period of time or when a trait is difficult to measure.

One of the statistical approaches used to estimate the genetic parameters is Bayesian inference, which uses posterior densities of the traits evaluated and can be applied in both small and large datasets without knowing the initial distribution of the parameter to be estimated, due to the fact that information is considered a priori $[9,10]$. Thus, the objective of the present paper was to 
estimate genetic parameters for weight gains from birth to weaning (BWGW) and to twelve months of age (WGW12) of Murrah, Mediterranean, and Jaffarabadi buffaloes raised in Brazil employing Bayesian inference.

\section{Materials and methods}

\subsection{Data}

Data belong to the Brazilian Bubalinos Genetic Improvement Program (PROMEBUL) and they refer to Mediterranean, Jaffarabadi, and Murrah buffalo breeds. Data editing was performed with SAS (SAS Institute, Cary, NC, USA), using BWGW and WGW12 as measured traits. Contemporary groups (CGs) included the herd, sex, year, and season of birth effects (December to March, April to July, and September to November). The CGs containing less than 3 animals were eliminated. Thus, a total of 405 Mediterranean animals $(C G=27), 766$ Jaffarabadi $(C G=$ $76)$, and 4675 Murrah $(C G=154)$ were evaluated.

\subsection{Statistical analysis}

The estimates of genetic parameters were determined using Bayesian inference with a two traits model using the GIBBS3F90 software [11], under the animal model. The matrix notation for the used model was $\mathrm{y}=\mathrm{X} \beta+\mathrm{Za}+$ $\mathrm{Mm}+\mathrm{Wep}+\mathrm{e}$, where $\mathrm{y}$ is the vector of observations of the dependent variable (BWGW and WGW12); $\mathrm{X}$ is the incidence matrix that relates the vector of the fixed effects to the observations; $\beta$ is the vector of the fixed effects (animal and $C G) ; Z$ is the incidence matrix that relates the direct additive genetic effects to the observations; $a$ is the vector of random effects representing the direct additive genetic values of each animal; $m$ is the vector of the random effects of maternal additive genetic value, associated to $y$ through the incidence matrix $\mathrm{M}$; ep is the vector of the maternal permanent environment random effects, associated to $\mathrm{y}$ through the incidence matrix $\mathrm{W}$; and $\mathrm{e}$ is the residual random effects vector. Reference values from the literature were used as a priori values.

An initial iteration number was obtained arbitrarily using a single chain with 400,000 iterations and burn-in of 40,000 samples, with a saving interval every 10 cycles (thin). The convergence diagnosis was carried out in $\mathrm{R}$ using the method of Raftery and Lewis [12], with the BOA package (Bayesian output analysis) [13]. The analysis proposed by Raftery and Lewis [12] includes the convergence for a stationary distribution and finds the necessary size of the chain to accurately estimate the quantiles of the functions of parameters [14]. The descriptive statistics of a posteriori distribution for each parameter were obtained from effective samples.

\section{Results}

The average weight gains of BWGW and WGW12 were $166.63 \pm 63.33 \mathrm{~g}$ and $103.42 \pm 52.27 \mathrm{~g}$ for the Mediterranean,
$153.99 \pm 52.08 \mathrm{~g}$ and $90.53 \pm 69.45 \mathrm{~g}$ for the Jaffarabadi, and $163.17 \pm 33.02 \mathrm{~g}$ and $163.17 \pm 90.99 \mathrm{~g}$ for the Murrah breeds, respectively. Heritabilities of maternal effect were, in general, of low magnitude and decreased with the increasing of age; however, despite the lower influence of maternal effects after weaning, these remain present until 12 months of age (Table 1).

In Mediterranean and Jaffarabadi breeds, the heritabilities of direct additive effect for WGW12 and BWGW were of low to moderate magnitude. On the other hand, the Murrah breed presented estimated heritability of direct additive effect of moderate magnitude for both characteristics. Genetic correlations (Table 2) for all traits in the evaluated breeds were of moderate magnitude, being higher in the Murrah breed. Phenotypic correlations ranged from low magnitude for the Murrah and Jaffarabadi breeds to moderate for the Mediterranean breed.

\section{Discussion}

Regarding the Mediterranean and Murrah breeds, the maternal effect was of little importance, suggesting that, at least in these two breeds, the total phenotypic variation for these traits substantially depends on the direct and environmental additive genetic effects. Differently, the Jaffarabadi breed showed higher values of maternal effects than direct ones. However, due to the lower weight gains, for both BWGW and WGW12, the maternal effect may not be properly exploited in the evaluated population.

Given that maternal ability is mainly due to milk production, these results suggest, in the case of dairy farming systems, that the quantity of milk that the buffalo provided to their offspring was insufficient to meet the requirements for growth, making it difficult to estimate the effect. According to Hossein-Zadeh [15], maternal influence contributes to the performance of the offspring and their participation in the evaluation models can provide producers with information to optimize the use of estimates when making selection decisions.

In general, the behavior of maternal effect observed in the Jaffarabadi breed is not common, being more frequently observed that additive effect is higher than maternal even in early ages. Problems estimating covariance between additive and maternal effects may occur when poorly structured populations or insufficient pedigree data are present [16]. The number of individuals in the Jaffarabadi breed is relatively reduced, and this may be the reason for the atypical behavior of additive and maternal effects.

Moreover, a recent study in dairy cattle reported that there are candidate genes for maternal effects [17], which directly affect the phenotypic variation if favorable alleles are segregating in the population. However, there is a lack of information about the genetic control of maternal effects in buffaloes, being important studies in this sense. 
REZENDE et al. / Turk J Vet Anim Sci

Table 1. Estimates of variance components for weight gain from birth to weaning (BWGW) and to twelve months of age (WGW12) of Murrah, Mediterranean, and Jaffarabadi buffaloes.

\begin{tabular}{|c|c|c|c|c|c|c|c|}
\hline & & Mean & SD & Median & Mode & \multicolumn{2}{|c|}{ Interval (95\%) } \\
\hline \multicolumn{8}{|c|}{ Mediterranean } \\
\hline & $\sigma^{2} \mathrm{a}$ & 177.47 & 90.61 & 164.20 & 147.00 & 55.78 & 349.00 \\
\hline & $\sigma^{2} \mathrm{~m}$ & 81.13 & 34.48 & 77.19 & 107.80 & 32.21 & 145.30 \\
\hline \multirow{6}{*}{ BWGW } & $\sigma^{2} \mathrm{ep}$ & 36.97 & 31.83 & 28.71 & 36.14 & 2.81 & 101.55 \\
\hline & $\sigma^{2} \mathrm{e}$ & 380.74 & 65.29 & 382.50 & 354.50 & 269.20 & 484.35 \\
\hline & $h^{2}$ & 0.26 & 0.12 & 0.24 & & 0.09 & 0.48 \\
\hline & $h^{2} \mathrm{~m}$ & 0.12 & 0.05 & 0.12 & & 0.05 & 0.21 \\
\hline & $\sigma^{2} \mathrm{a}$ & 178.63 & 91.46 & 164.70 & 120.70 & 56.00 & 345.30 \\
\hline & $\sigma^{2} \mathrm{~m}$ & 79.83 & 32.17 & 75.42 & 107.40 & 35.87 & 139.70 \\
\hline \multirow{4}{*}{ WGW12 } & $\sigma^{2} \mathrm{ep}$ & 48.06 & 29.79 & 41.80 & 33.63 & 11.56 & 105.10 \\
\hline & $\sigma^{2} \mathrm{e}$ & 597.95 & 76.15 & 598.70 & 598.50 & 471.40 & 721.95 \\
\hline & $\mathrm{h}^{2}$ & 0.19 & 0.09 & 0.18 & 0.30 & 0.07 & 0.36 \\
\hline & $h^{2} \mathrm{~m}$ & 0.09 & 0.03 & 0.08 & 0.10 & 0.04 & 0.15 \\
\hline \multicolumn{8}{|c|}{ Jaffarabadi } \\
\hline & $\sigma^{2} \mathrm{a}$ & 148.53 & 101.42 & 122.45 & 104.80 & 35.34 & 353.85 \\
\hline & $\sigma^{2} \mathrm{~m}$ & 169.34 & 52.02 & 166.95 & 169.80 & 88.18 & 259.70 \\
\hline \multirow{6}{*}{ BWGW } & $\sigma^{2} \mathrm{ep}$ & 44.55 & 41.82 & 31.49 & 11.12 & 1.73 & 128.95 \\
\hline & $\sigma^{2} \mathrm{e}$ & 513.92 & 78.21 & 519.90 & 526.70 & 371.30 & 628.95 \\
\hline & $\mathrm{h}^{2}$ & 0.17 & 0.11 & 0.14 & 0.15 & 0.04 & 0.38 \\
\hline & $\mathrm{h}^{2} \mathrm{~m}$ & 0.19 & 0.06 & 0.19 & & 0.10 & 0.29 \\
\hline & $\sigma^{2} \mathrm{a}$ & 343.03 & 153.19 & 326.00 & 296.60 & 123.15 & 619.20 \\
\hline & $\sigma^{2} \mathrm{~m}$ & 132.73 & 47.86 & 129.00 & 136.60 & 63.27 & 218.45 \\
\hline \multirow{4}{*}{ WGW12 } & $\sigma^{2} \mathrm{ep}$ & 44.39 & 29.61 & 39.06 & 13.15 & 6.89 & 99.21 \\
\hline & $\sigma^{2} \mathrm{e}$ & 698.14 & 115.43 & 705.00 & 626.50 & 498.30 & 877.95 \\
\hline & $\mathrm{h}^{2}$ & 0.28 & 0.11 & 0.27 & 0.50 & 0.11 & 0.48 \\
\hline & $h^{2} \mathrm{~m}$ & 0.11 & 0.04 & 0.11 & 0.09 & 0.05 & 0.18 \\
\hline \multicolumn{8}{|l|}{ Murrah } \\
\hline & $\sigma^{2} \mathrm{a}$ & 338.52 & 43.61 & 336.80 & 335.40 & 266.70 & 413.40 \\
\hline & $\sigma^{2} \mathrm{~m}$ & 41.90 & 13.92 & 41.02 & 30.00 & 21.00 & 67.01 \\
\hline \multirow{6}{*}{ BWGW } & $\sigma^{2} \mathrm{ep}$ & 62.54 & 18.20 & 61.82 & 68.07 & 34.61 & 93.98 \\
\hline & $\sigma^{2} \mathrm{e}$ & 372.81 & 30.69 & 372.90 & 370.10 & 321.30 & 423.40 \\
\hline & $h^{2}$ & 0.41 & 0.048 & 0.41 & 0.37 & 0.33 & 0.49 \\
\hline & $\mathrm{h}^{2} \mathrm{~m}$ & 0.05 & 0.02 & 0.05 & 0.06 & 0.03 & 0.08 \\
\hline & $\sigma^{2} a$ & 317.25 & 46.88 & 314.70 & 294.00 & 244.10 & 397.40 \\
\hline & $\sigma^{2} \mathrm{~m}$ & 16.47 & 6.07 & 15.68 & 15.09 & 7.48 & 27.85 \\
\hline \multirow{4}{*}{ WGW12 } & $\sigma^{2} \mathrm{ep}$ & 11.65 & 5.70 & 10.43 & 11.27 & 4.67 & 23.46 \\
\hline & $\sigma^{2} \mathrm{e}$ & 705.90 & 38.43 & 706.40 & 705.10 & 641.00 & 768.30 \\
\hline & $h^{2}$ & 0.30 & 0.041 & 0.30 & & 0.23 & 0.37 \\
\hline & $h^{2} m$ & 0.02 & 0.01 & 0.01 & & 0.01 & 0.03 \\
\hline
\end{tabular}

$\sigma^{2} \mathrm{a}$ : Additive genetic variance, $\sigma^{2} \mathrm{~m}$ : maternal genetic variance, $\sigma^{2} \mathrm{ep}$ : permanent effect variance, $\sigma^{2} \mathrm{e}$ : proportion of the environmental variance over the phenotypic variance, $h^{2} \mathrm{a}$ : heritability of direct additive effect, $h^{2} \mathrm{~m}$ : heritability of the maternal effect. SD: Standard error. 
Table 2. Genetic and phenotypic correlations between weight gains from birth to weaning (BWGW) and to twelve months of age (WGW12) of Murrah, Mediterranean, and Jaffarabadi buffaloes.

\begin{tabular}{|l|l|l|l|}
\hline & Mediterranean & Jaffarabadi & Murrah \\
\hline & BWGW $\times$ WGW12 & BWGW $\times$ WGW12 & BWGW $\times$ WGW12 \\
\hline GC & $0.64^{*}$ & $0.51^{*}$ & $0.70^{*}$ \\
\hline PC & $0.61^{\star}$ & $0.45^{\star}$ & $0.26^{*}$ \\
\hline
\end{tabular}

GC: Genetic correlation, PC: phenotypic correlation, ${ }^{\star} \mathrm{P}<0.001$ (significant difference).

Maternal heritability was influenced by the uterine environment, as well as the other factors related to gestation and the mother's abilities during the weaning phase [18]. The maternal genetic and maternal permanent environmental variances were higher in BWGW than in WGW12, similarly to other research in buffaloes [19]. These variances decreased at later ages, which is the probable reason for lower maternal heritabilities of WGW12 when compared to BWGW. The maternal effects are more important until weaning, and if this effect is not accounted for when it exists there may be losses in growth in this period, as pointed out by Boligon et al. [20] in a study with beef cattle.

The reduction of maternal effects at later ages can be explained by the offspring's independence from maternal care; that is, the ability of the offspring to gain weaning weight up to one year of age depends more on the direct genetic effect than on the maternal effect. Bolivar et al. [19] studying Colombian buffaloes reported the reduction of maternal heritability during animal growth and advocated the implementation of a screening program for direct and maternal growth traits to improve performance levels within the property and population.

Malhado et al. [3] reported that maternal heritabilities for body weight at 205 and 305 days in Mediterranean buffalo were of low magnitude $(0.05 \pm 0.03$ for both characteristics). Although there are differences in rearing systems of buffaloes between Brazil and Colombia, similar results were obtained by Bolívar et al. [19], studying the genetic parameters for body weight in Colombian buffalo via random regression. Maternal heritability at birth was $0.01 \pm 0.03$ and it increased until weaning $(0.11 \pm 0.05)$, stabilizing at 340 days of age.

In Brazilian buffaloes, Aguiari et al. [18] observed estimates of maternal heritability for birth weight of 0.14 \pm 0.05 in the Murrah $\times$ Mediterranean cross, suggesting that maternal effect similarly acts independently of the trait. Selection of animals based on the maternal ability for body weight should be made close to weaning as maternal heritability reaches higher values at this time [19] and the present results confirmed this fact. Heritability estimates of the direct additive effect for BWGW and WGW12 on the Mediterranean and Jaffarabadi breeds indicated average importance of the additive genetic variation in the transmission of the characteristics.

As for the Murrah breed, on the other hand, a greater genetic gain can be achieved through selection, and faster than in the other breeds. In general, improvement programs in buffaloes are recent and the herds are almost exclusively reared for dual purposes (milk and meat). Therefore, there is raw genetic material to be explored, and research about covariance components in buffaloes can provide available information useful to determine the objective and selection criteria.

In general, the estimates of direct heritability (BWGW and WGW12) for the three breeds (except BWGW in Jaffarabadi) were higher than estimates of maternal heritability, suggesting that the direct genetic effect is more important to determine the weight gain of the animals compared to the maternal genetic effect. According to Rosales-Aldey et al. [21], the importance of maternal genetic effects in buffalo populations should not be ignored, especially under tropical conditions, whose production system depends on the milk production and duration of lactation of the mother.

Differences among estimated heritabilities, both direct and maternal, in the different buffalo breeds found in this research may have occurred due to the structure of the studied populations and to the fact that body weight gain is a feature strongly influenced by the feeding management and seasonal supply of fodder crops. The estimated values of heritability may vary according to the population, the methodology used, and the model of analysis [18]. Thus, the selected method of analysis could have influenced heritability through its effect on additive and residual variances.

In general, the estimates of direct heritability for body weight characteristics in cattle are moderate to high $[22,23]$, whereas no works reporting estimates of genetic parameters of body weight gains were found for buffaloes. Malhado et al. [3] found estimates of direct heritability for weights adjusted to 205,365 , and 550 days of age ranging 
from 0.41 to 0.50 in Mediterranean buffaloes, which were higher than the values observed in BWGW and WGW12 in this study. However, there is a possibility of direct selection for daily gains in the buffalo populations evaluated. It is thus necessary to deepen and broaden the studies on genetic parameters of weight gains at various ages in buffaloes to precisely determine the genetic component of these traits.

Estimates of genetic correlations between BWGW and WGW12 in buffaloes are also rare in the literature. The genetic correlations between body weights of buffaloes at various ages are moderate to high [19,24], presenting a behavior similar to that observed for BWGW and WGW12 for all the breeds studied here. Genetic correlations indicated that the selection for weight gains at younger ages leads to an increase in weight gains at 12 months, which allows producing more precocious buffalo animals.

It is hypothesized that these correlations do not present higher values due to the management commonly used in the production of buffaloes; indeed, during the weaning period, limited quantities of milk are supplied, since the producers seek to use milk as a source of income. Therefore, it is not possible to observe maternal ability in a reliable manner. This hypothesis can also be considered for maternal heritability.

\section{References}

1. Araújo CV, Cardoso ADC, Ramos ADA, Araújo SI, Marques JRF et al. Genetic parameters and heterogeneity of variance to milk yield in Murrah breed for Bayesian inference. Revista Brasileira de Saúde e Producão Animal 2008; 9 (3): 416-425.

2. Malhado CHM, Ramos AA, Carneiro PLS, Azevedo DMM R, Affonso PDM et al. Genetic parameters of reproductive and productive traits in cross-breed water buffaloes in Brazil. Revista Brasileira de Saúde e Produção Animal 2009; 10 (4): 830-839.

3. Malhado CHM, Ramos AA, Carneiro PLS, Azevedo DMMR, Martins Filho R et al. Melhoramento e estrutura populacional em bubalinos da raça Mediterrâneo no Brasil. Pesquisa Agropecuária Brasileira 2008; 43 (2): 215-220 (in Portuguese).

4. Malhado CHM, Carneiro PLS, Ramos AA, Souza JC, Ferraz Filho PB et al. Analyze of the weighting distribution in different ages from Mediterranean buffaloes. Revista Científica de Produção Animal 2004; 6 (2): 40-48.

5. Tonhati H, Muñoz MFC, Duarte JMC, Reichert RH, Oliveira JÁ et al. Estimates of correction factors for lactation length and genetic parameters for milk yield in buffaloes. Arquivo Brasileiro de Medicina Veterinária e Zootecnia 2004; 56 (2): 251-257. doi: 10.1590/S0102-09352004000200016

6. Rodrigues AE, Marques JRF, Araújo CV, Camargo Júnior RNC, Dias LNS. Estimation of genetic parameters of dairy buffaloes productive characteristics Eastern Amazon. Arquivo Brasileiro de Medicina Veterinária e Zootecnia 2010; 62 (3): 712-717. doi: 10.1590/S0102-09352010000300028
Genetic and phenotypic correlations were similar for the Mediterranean and Jaffarabadi breeds, whereas for the Murrah breed phenotypic correlation is approximately three times lower than genetic, indicating how the environment acts to mask genotype expression. Knowledge about genetic correlations is important to determine the correlated response, which is important to get a global improvement of the animals, and this information is also scarce in buffaloes.

The interest in buffalo husbandry has increased due to the demand for their products, which are well accepted in the market. Buffalo's milk is richer in protein, fat, lactose, and energy than cow's milk and buffalo has a greater potential of meat production [25]. It is possible to select buffaloes in early ages because weight gains show sufficient genetic control and are highly correlated in all breeds. Therefore, the improvement of buffaloes should match the demand for their products, and the estimation of genetic parameters is the first step to implement a genetic evaluation, which should be followed by the other routine practices of breeding programs.

\section{Conflict of interest}

The authors declare that they have no conflict of interest.

7. Vergara DMB, Munoz MC, Toro EJR, Gomez DAA, Cifuentes T. Genetic parameters for growth traits of buffaloes (Bubalus bubalis Artiodactyla, Bovidae) in Colombia. Revista Colombiana de Ciencias Pecuarias 2012; 25 (2): 202-209.

8. Vercesi Filho AE, Madalena FE, Albuquerque LG, Freitas AF, Borges LE et al. Genetic parameters between milk traits, weight traits and age at first calving in crossbreed dairy cattle (Bos taurus x Bos indicus). Arquivo Brasileiro de Medicina Veterinária e Zootecnia 2007; 59 (4): 983-990. doi: 10.1590/ S0102-09352007000400026

9. Faria CUD, Magnabosco CDU, Reyes ADL, Lôbo RB, Bezerra LAF. Bayesian inference and its application in the genetic evaluation of the Nellore cattle: Bibliographic Review. Ciência Animal Brasileira 2007; 8 (1): 75-86.

10. Silva FF, Sáfadi T, Muniz JA, Aquino LHD, Mourão GB. Bayesian comparison of forecasting models to expected progenies difference in Nelore cattle genetic breeding. Pesquisa Agropecuária Brasileira 2008; 43 (1): 37-45. doi: 10.1590/ S0100-204X2008000100006

11. Misztal J. Fortran Programs. Athens, GA, USA: University of Georgia; 2012.

12. Raftery AE, Lewis S. How many iterations in the Gibbs sampler? In: Dawid AP (editor). Bayesian Statistics 4. Oxford, UK: Oxford University Press; 1992. pp. 763-773. 
13. Smith BJ. Boa: An R package for MCMC output convergence assessment and posterior inference. Journal of Statistical Software 2007; 21 (11): 1-37.

14. Barbosa L, Lopes PS, Regazzi AJ, Torres RDA, Santana Junior ML et al. Estimation of genetic parameters for growth and backfat thickness of Large White pigs using the Gibbs Sampler. Revista Brasileira de Zootecnia 2008; 37 (7): 12001206. doi: 10.1590/S1516-35982008000700009

15. Hossein-Zadeh NG. Bayesian analysis of direct and maternal effects for birthweight in Iranian buffaloes using Gibbs sampling. Animal Production Science 2016; 56 (5): 859-865. doi: $10.1071 /$ AN14564

16. Boligon AA, Pereira RJ, Ayres DR, Albuquerque LG. Influence of data structure on the estimation of the additive genetic direct and maternal covariance for early growth traits in Nellore cattle. Livestock Science 2012; 145(1): 212-218. doi: 10.1016/j. livsci.2012.02.004

17. Yin T, König S. Genome-wide associations and detection of potential candidate genes for direct genetic and maternal genetic effects influencing dairy cattle body weight at different ages. Genetics Selection and Evolution 2019; 51(1): 4-18. doi: 10.1186/s12711-018-0444-4

18. Aguiari JF, Marcondes CR, Marques JRF, Vozzi PA, Camargo J et al. Genetic variability of birth weight and selection for growth of water buffaloes from State of Pará, Brazil. Acta Amazônica 2014; 44 (3): 373-378. doi: 10.1590/1809-4392201303305

19. Bolívar DM, Cerón-Muñoz MF, Boligon AA, Elzo MA, Herrera AC. Genetic parameters for body weight in buffaloes (Bubalus bubalis) in Colombia using random regression models. Livestock Science 2013; 158 (1-3): 40-49. doi: 10.1016/j.livsci.2013.10.015
20. Boligon AA, Vicente IS, Roso VM, Souza FRB. Direct and maternal annual genetic changes for selected traits at weaning and yearling in beef cattle. Acta Scienctiarium Anima Science 2019; 41(1): 42572-42591. doi: 10.4025/actascianimsci. v41i1.42572

21. Rosales-Alday J, Enzo MA, Bermúdez MM, Murillo VEV, Valdez AR. Parámetros genéticos para pesos al Nacimiento y destete en Ganado Simmental-Brahman en el subtrópico mexicano. Técnica Pecuaria en México 2004; 42 (33): 333-346 (in Spanish).

22. Baldi F, Alencar MMD, Albuquerque LGD. Estimation of genetic parameters for growth traits in Canchim cattle with finite models. Revista Brasileira de Zootecnia 2010; 39 (11): 2409-2417. doi: 10.1590/S1516-35982010001100013

23. Boligon AA, Mercadante MEZ, Forni S, Lôbo RB, Albuquerque LGD. Covariance functions for body weight from birth to maturity in Nellore cows. Journal of Animal Science 2010; 88 (3): 849-859. doi: $10.2527 /$ jas.2008-1511

24. Malhado CHM, Malhado ACM, Ramos AA, Carneiro PLS, Siewerdt $\mathrm{F}$ et al. Genetic parameters by Bayesian inference for dual purpose Jaffarabadi buffaloes. Archives Animal Breeding 2012; 55 (6): 567-576. doi: 10.5194/aab-55-567-2012

25. Safari A, Hossein-Zadeh NG, Shadparvar AA, Arpanahi RA. A review on breeding and genetic strategies in Iranian buffaloes (Bubalus bubalis). Tropical Animal Health and Production 2018; 70 (4) 707-714. doi: 10.1007/s11250-018-1563-1 